Article

\title{
A Facile One-Pot Approach to the Synthesis of Gd-Eu Based Metal-Organic Frameworks and Applications to Sensing of $\mathrm{Fe}^{3+}$ and $\mathrm{Cr}_{2} \mathrm{O}_{7}^{2-}$ Ions
}

\author{
Roberta Puglisi $^{1,+}$, Anna L. Pellegrino ${ }^{2,+}\left(\mathbb{D}\right.$, Roberto Fiorenza $^{1}\left(\mathbb{D}\right.$, Salvatore Scirè ${ }^{1}(\mathbb{D})$ and \\ Graziella Malandrino 2 **(D) \\ 1 Dipartimento di Scienze Chimiche, Università degli Studi di Catania, Viale Andrea Doria 6, \\ I-95125 Catania, Italy; robertapuglisi90@gmail.com (R.P.); rfiorenza@unict.it (R.F.); sscire@unict.it (S.S.) \\ 2 Dipartimento di Scienze Chimiche, Università degli Studi di Catania, INSTM UdR Catania, \\ Viale Andrea Doria 6, I-95125 Catania, Italy; annalucia.pellegrino@unict.it \\ * Correspondence: graziella.malandrino@unict.it; Tel.: +39-095-7385055 \\ + These authors have contributed equally to the study.
}

check for updates

Citation: Puglisi, R.; Pellegrino, A.L.; Fiorenza, R.; Scirè, S.; Malandrino, G. A Facile One-Pot Approach to the Synthesis of Gd-Eu Based MetalOrganic Frameworks and Applications to Sensing of $\mathrm{Fe}^{3+}$ and $\mathrm{Cr}_{2} \mathrm{O}_{7}{ }^{2-}$ Ions. Sensors 2021, 21, 1679. https://doi.org/10.3390/s21051679

Academic Editor:

Georgia-Paraskevi Nikoleli

Received: 30 December 2020

Accepted: 24 February 2021

Published: 1 March 2021

Publisher's Note: MDPI stays neutral with regard to jurisdictional claims in published maps and institutional affiliations.

Copyright: (C) 2021 by the authors. Licensee MDPI, Basel, Switzerland. This article is an open access article distributed under the terms and conditions of the Creative Commons Attribution (CC BY) license (https:// creativecommons.org/licenses/by/ $4.0 /)$

\begin{abstract}
Gadolinium metal-organic frameworks (Gd-MOFs) and Eu-doped Gd-MOFs have been synthesized through a one-pot green approach using commercially available reagents. The 1,4benzenedicarboxylic acid ( $\mathrm{H}_{2}$-BDC) and 2,6-naphthalenedicarboxylic acid $\left(\mathrm{H}_{2}-\mathrm{NDC}\right)$ were chosen as ditopic organic linkers to build the 3D structure of the network. The Gd-MOFs were characterized using powder X-ray diffraction (XRD), FT-IR spectroscopy, field emission scanning electron microscopy (FE-SEM) and $\mathrm{N}_{2}$ adsorption-desorption analysis. The Gd-MOF structures were attributed comparing the XRD patterns, supported by the FT-IR spectra, with data reported in the literature for Ln-MOFs of similar lanthanide ionic radius. FE-SEM characterization points to the effect of the duration of the synthesis to a more crystalline and organized structure, with grain dimensions increasing upon increasing reaction time. The total surface area of the MOFs has been determined from the application of the Brunauer-Emmett-Teller method. The study allowed us to correlate the processing conditions and ditopic linker dimension to the network surface area. Both Gd-MOF and Eu-doped Gd-MOF have been tested for sensing of the inorganic ions such as $\mathrm{Fe}^{3+}$ and $\mathrm{Cr}_{2} \mathrm{O}_{7}{ }^{2-}$.
\end{abstract}

Keywords: Gd,Eu-MOF; ion sensing; X-ray powder pattern; ditopic linkers; porosity; surface area

\section{Introduction}

During the last decades, metal-organic frameworks (MOF) have shown interesting properties which lead to important applications in several fields of material science such as energy transfer and light-harvesting [1,2], gas storage [3-5], adsorption of hydrocarbons [6,7], sensing [8,9], catalysis [10-12] and ferroelectrics [13]. In addition, MOFs represent platforms for functional materials [14] and recently they have been found appealing for photovoltaic applications [15]. The advantages of these materials are the possibility of tuning their properties by easily altering the structure, e.g., by changing the metallic center, the organic linkers and the synthetic operating conditions such as duration, temperature and pressure. In regard to the linker, a variety of multitopic spacer have been applied and a plethora of MOF structures have been obtained [16]. These materials are composed of organic secondary subunits and/or metal containing ones. The shape of these clusters can be assimilated to specific geometric structures, such as triangular ones, tetrahedral or octahedral in periodically organized systems. For example, among the most studied MOFs of transition metals, there are the MOF-5 and IRMOF-5, consisting of $\mathrm{Zn}_{4} \mathrm{O}$-cluster subunits with 1,4-benzendicarboxylic acid and $\mathrm{Zn}_{4} \mathrm{O}$-clusters with 2,6-naphthalendicarboxylic acid [17-19].

In regard to the metal center, great attention has been devoted to transition metals, due to their appealing properties tunable by molecular design [20-22]. Recently, the attention 
has moved to lanthanides ( $\mathrm{Ln}$ ) due to their fascinating properties ranging from metal ion sensing to ratiometric thermometry, from magnetic to luminescence, from gas and dyes adsorption to catalysis. A comprehensive view of the various application fields of Ln-MOF can be found in the reviews [23-25] and references therein.

The use of these elements allowed the development of specific properties and in particular Eu-based MOFs have recently attracted great attention, due to their applications to sensing a great variety of species. Many studies have been carried out on the detection of pollutants, such as some inorganic ions in water, because these chemical species pose serious problems for water contamination. In particular, the detection process of inorganic cations and toxic anions is primarily based on quenching of fluorescence phenomena, arising from europium ions sensitized by the MOF ligand through the "antenna effect" [26-31]. The Eu-based MOFs have also been applied to detect antibiotics, which are widely used for the treatment of bacterial infections and are excreted generating major organic pollutants in water [28,32]. The Eu-based MOFs have also been shown to be highly sensitive for nitroaromatic explosives [32,33], and have been tested for detection of amino acids [34] and adsorption of dyes [35,36].

Up to date, syntheses of Ln-MOFs have been essentially carried out through microwave, electrochemical or mechanochemical processes and solvothermal route [37-39], where high pressure, organic solvents and, in some cases, very long reaction times are required. Recently, the need to develop an up-scalable, green synthetic process, of great interest in terms of industrial requirements, has been the focus of a review addressing the green synthesis of transition metal MOFs [40].

In this context, a green, one-step route under mild conditions is highly desirable for the synthesis of Ln-MOFs in large scale in a controlled and reproducible fashion. Furthermore, an added value for these systems would be their stability in water, which would allow their applications for highly selective and sensitive luminescence sensing for ions and antibiotics in aqueous solutions.

In this study, we report a one-pot approach under mild conditions of Gd-MOF networks and 20\% Eu-doped Gd-MOF based on the ditopic 1,4-benzenedicarboxylic acid $\left(\mathrm{H}_{2}\right.$-BDC) or 2,6-naphthalenedicarboxylic acid $\left(\mathrm{H}_{2}-\mathrm{NDC}\right)$ linkers, yielding respectively the $\left[\mathrm{Gd}_{2}(\mathrm{BDC})_{3}\left(\mathrm{H}_{2} \mathrm{O}\right)_{4}\right]$ and $\left[\mathrm{Gd}_{1.6} \mathrm{Eu}_{0.4}(\mathrm{BDC})_{3}\left(\mathrm{H}_{2} \mathrm{O}\right)_{4}\right]$, from now on Gd-BDC and $\mathrm{Gd}$,Eu$\mathrm{BDC}$, and the $\left[\mathrm{Gd}_{2}(\mathrm{NDC})_{3}\left(\mathrm{H}_{2} \mathrm{O}\right)\right] \cdot 2\left(\mathrm{H}_{2} \mathrm{O}\right), \mathrm{Gd}-\mathrm{NDC}$ networks. The X-ray diffraction (XRD) and field emission scanning electron microscopy (FE-SEM) allowed to study the effect of the reaction time on the structural and morphological properties, while the $\mathrm{N}_{2}$ physisorption, using the Brunauer-Emmett-Teller (BET) method [41], allowed to rationalize the textural properties (surface area) of the system in relation to the ditopic linker and the reaction time. Finally, based on the luminescence study, the Gd-BDC and Gd,Eu-BDC MOFs have been applied to the sensing of $\mathrm{Fe}^{3+}$ and $\mathrm{Cr}_{2} \mathrm{O}_{7}{ }^{2-}$ inorganic ions in aqueous solutions.

\section{Materials and Methods}

\subsection{Materials}

Gadolinium(III) and europium(III) acetates tetrahydrate were purchased from STREM Chemicals, while the 1,4-benzenedicarboxylic acid and the 2,6-naphthalene-dicarboxylic acid were purchased from Sigma-Aldrich. Deionized water was used as solvent.

\subsection{Synthesis of $\left[\mathrm{Gd}_{2}(\mathrm{BDC})_{3}\left(\mathrm{H}_{2} \mathrm{O}\right)_{4}\right]$}

An amount of $1.2138 \mathrm{~g}(2.99 \mathrm{mmol})$ of $\mathrm{Gd}\left(\mathrm{CH}_{3} \mathrm{COO}\right)_{3} \cdot 4 \mathrm{H}_{2} \mathrm{O}$ was placed in a groundedneck glass balloon. Then, $0.358 \mathrm{~g}$ of $\mathrm{NaOH}$ and $30 \mathrm{~mL}$ of deionized $\mathrm{H}_{2} \mathrm{O}$ were added and the whole system was placed over a magnetic stirrer plate. It was possible to appreciate the immediate precipitation of Gd-hydroxide. The temperature was then raised to $100{ }^{\circ} \mathrm{C}$ and after about $5 \mathrm{~min} 0.7443 \mathrm{~g}(4.48 \mathrm{mmol})$ of $\mathrm{H}_{2}-\mathrm{BDC}$ were added. A white precipitate formed immediately and was left stirring under reflux for 1, 6, 12 and $24 \mathrm{~h}$, respectively. After the chosen reaction time, the MOF precipitate was recovered by filtration, while the Na-acetate by-product, soluble in water, was easily removed in the liquid waste. The product was washed with $\mathrm{H}_{2} \mathrm{O}$ and dried at room temperature. Yields were about $80-84 \%$. 


\subsection{Synthesis of $\left[G d_{1.6} E u_{0.4}(B D C)_{3}\left(\mathrm{H}_{2} \mathrm{O}\right)_{4}\right]$}

The Gd,Eu-BDC compound was synthesized following a procedure similar to that described for the analogous Gd-BDC compound from $\mathrm{Gd}\left(\mathrm{CH}_{3} \mathrm{COO}\right)_{3} \cdot 4 \mathrm{H}_{2} \mathrm{O}(0.970 \mathrm{~g}$, $2.39 \mathrm{mmol}), \mathrm{Eu}\left(\mathrm{CH}_{3} \mathrm{COO}\right)_{3} \cdot 4 \mathrm{H}_{2} \mathrm{O}(0.240 \mathrm{~g}, 0.6 \mathrm{mmol}), \mathrm{NaOH}(0.358 \mathrm{~g}, 8.96 \mathrm{mmol})$ and $\mathrm{H}_{2}$-BDC ( $\left.0.7443 \mathrm{~g}, 4.48 \mathrm{mmol}\right)$. Yields were about $84-86 \%$.

\subsection{Synthesis of $\left[\mathrm{Gd}_{2}(\mathrm{NDC})_{3}\left(\mathrm{H}_{2} \mathrm{O}\right)\right] \cdot 2\left(\mathrm{H}_{2} \mathrm{O}\right)$}

The Gd-NDC compound was synthesized following the procedure described for the analogous Gd-BDC compound from $\mathrm{Gd}\left(\mathrm{CH}_{3} \mathrm{COO}\right)_{3} \cdot 4 \mathrm{H}_{2} \mathrm{O}(1.2137 \mathrm{~g}, 2.99 \mathrm{mmol}), \mathrm{NaOH}$ $(0.360 \mathrm{~g}, 8.96 \mathrm{mmol})$ and $\mathrm{H}_{2}$-NDC $(0.9685 \mathrm{~g}, 4.48 \mathrm{mmol})$. Yields were about $82-85 \%$.

\subsection{Gd-MOF Characterization}

Fourier transform infrared (FT-IR) spectra were recorded on an FT-IR-430 JASCO spectrometer. FT-IR spectra were recorded on nujol mull of the samples placed between $\mathrm{KBr}$ plates. XRD patterns were recorded on a Smartlab Rigaku diffractometer, equipped with a rotating anode of $\mathrm{Cu} \mathrm{K} \alpha$ radiation operating at $45 \mathrm{kV}$ and $200 \mathrm{~mA}$. A $0.02^{\circ}$ increment step was used for the acquisition. In order to characterize the synthesized Gd-MOF through FE-SEM images, the samples were stuck on $\mathrm{Al}$ stub by means of graphite double-sided adhesives. The samples were sputtered with $\mathrm{Au}$ in order to avoid excessive charging effects due to their non-conductive nature. FE-SEM images were taken using a ZEISS SUPRA $55 \mathrm{VP}$ field emission microscope. To reduce the charging effect and to avoid sputtering with $\mathrm{Au}$ a low voltage of $3 \mathrm{kV}$ was used. Energy dispersive $\mathrm{X}$-Ray analyses were carried out using an Oxford X-ACTA detector with a beam energy of $15 \mathrm{keV}$. The $\mathrm{N}_{2}$ adsorptiondesorption experiments were carried out in a Sorptomatic 1990 Micropore configuration (Thermo Quest). Before tests, the samples were degassed at $120{ }^{\circ} \mathrm{C}$ at $10^{-3}$ Torr. The physisorption experiments were performed at liquid nitrogen boiling temperature (77 K). Surface area was evaluated with the help of a fully computerized unit attached to the Micropore unit system using the BET equation [41].

For each experiment of sensing, $2 \mathrm{mg}$ of $\left[\mathrm{Gd}_{1.6} \mathrm{Eu}_{0.4}(\mathrm{BDC})_{3}\left(\mathrm{H}_{2} \mathrm{O}\right)_{4}\right]$ was dispersed in $2 \mathrm{~mL}$ of water. After that, various rates of $\mathrm{FeCl}_{3} 1 \times 10^{-2} \mathrm{M}$ or $\mathrm{K}_{2} \mathrm{Cr}_{2} \mathrm{O}_{7} 1 \times 10^{-2} \mathrm{M}$ contaminant solutions were added in the $\left[\mathrm{Gd}_{1.6} \mathrm{Eu}_{0.4}(\mathrm{BDC})_{3}\left(\mathrm{H}_{2} \mathrm{O}\right)_{4}\right]$ dispersion. The mixtures were used after $5 \mathrm{~min}$ of sonication treatment after each addition for luminescence measurements. Sequential $\mathrm{Fe}^{3+}$ detection tests were carried out using the same $\mathrm{Gd}, \mathrm{Eu}-\mathrm{BDC}$ MOF powder. After each detection test, the suspension was centrifuged for $10 \mathrm{~min}$ in order to remove the contaminant solution and was washed with $\mathrm{H}_{2} \mathrm{O}$ before the next sensing test. Photoluminescence spectra were collected at room temperature using a JASCO FP-8300 spectrofluorimeter at $\lambda$ excitation of 265 or $285 \mathrm{~nm}$.

\section{Results and Discussion}

\subsection{Synthesis of Gd-MOFs with Ditopic Linkers}

Two different types of Gd-MOFs have been synthesized using ditopic linkers such as 1,4-benzenedicarboxylic acid $\left(\mathrm{H}_{2}-\mathrm{BDC}\right)$ and the 2,6-naphthalene-dicarboxylic acid $\left(\mathrm{H}_{2-}\right.$ $\mathrm{NDC}$ ), whose carboxylated functions are capable to fit the coordination prerequisite of the metallic center and generate the hybrid polymeric structure. The Gd-BDC MOF has been also doped with Eu ion.

The syntheses have been carried out using commercially available reagents, under mild conditions of pressure and temperature. In addition, the use of water as a solvent characterizes this synthetic approach as an absolutely green route. All the syntheses were carried out under reflux conditions, while the reaction times were varied from $1 \mathrm{~h}$ to $24 \mathrm{~h}$ to correlate the structural/morphological properties to the synthetic conditions.

The synthesis of the Gd-MOFs with $\mathrm{H}_{2}-\mathrm{BDC}$ and $\mathrm{H}_{2}-\mathrm{NDC}$ acids is described in Equations (1) and (2), respectively: 
$2 \mathrm{Gd}\left(\mathrm{CH}_{3} \mathrm{COO}\right)_{3} \cdot 4 \mathrm{H}_{2} \mathrm{O}+3 \mathrm{H}_{2}-\mathrm{NDC}+6 \mathrm{NaOH} \rightarrow\left[\mathrm{Gd}_{2}(\mathrm{NDC})_{3}\left(\mathrm{H}_{2} \mathrm{O}\right)\right] \cdot 2\left(\mathrm{H}_{2} \mathrm{O}\right)+6 \mathrm{CH}_{3} \mathrm{COONa}+10 \mathrm{H}_{2} \mathrm{O}$

The present synthetic strategy represents a simple, one-pot route to the formation of Ln-MOF with respect to the time demanding solvothermal processes. It also presents some advantages with respect to the previously reported syntheses carried out in water [42,43], which require three different steps, namely, (i) the synthesis of the lanthanide chlorides through reaction of the respective oxides with hydrochloric acid; (ii) synthesis of the sodium salt of the carboxylic acid; (iii) synthesis of the Gd-MOF from the formerly synthesized reagents.

\subsection{Structural, Morphological and Compositional Properties of $\left[G d_{2}(B D C)_{3}\left(H_{2} \mathrm{O}\right)_{4}\right]$}

All the syntheses, whatever the duration time, yielded crystalline samples. In Figure 1a, a comparison between the X-ray diffraction (XRD) patterns of Gd-BDC samples obtained at 1 and $24 \mathrm{~h}$ is reported. The reaction time, being the reaction temperature $100^{\circ} \mathrm{C}$ for all the syntheses, has a slight effect on crystallinity. The diffraction pattern has been interpreted by comparison with literature data. In fact, it has been reported that $\mathrm{M}_{2}(\mathrm{BDC})_{3}\left(\mathrm{H}_{2} \mathrm{O}\right)_{4}$ samples, where $\mathrm{M}$ is a small ionic radius lanthanide, have isomorphic structures, while the patterns are slightly different if $\mathrm{M}$ is a lanthanide with a larger ionic radius, for example La [43].
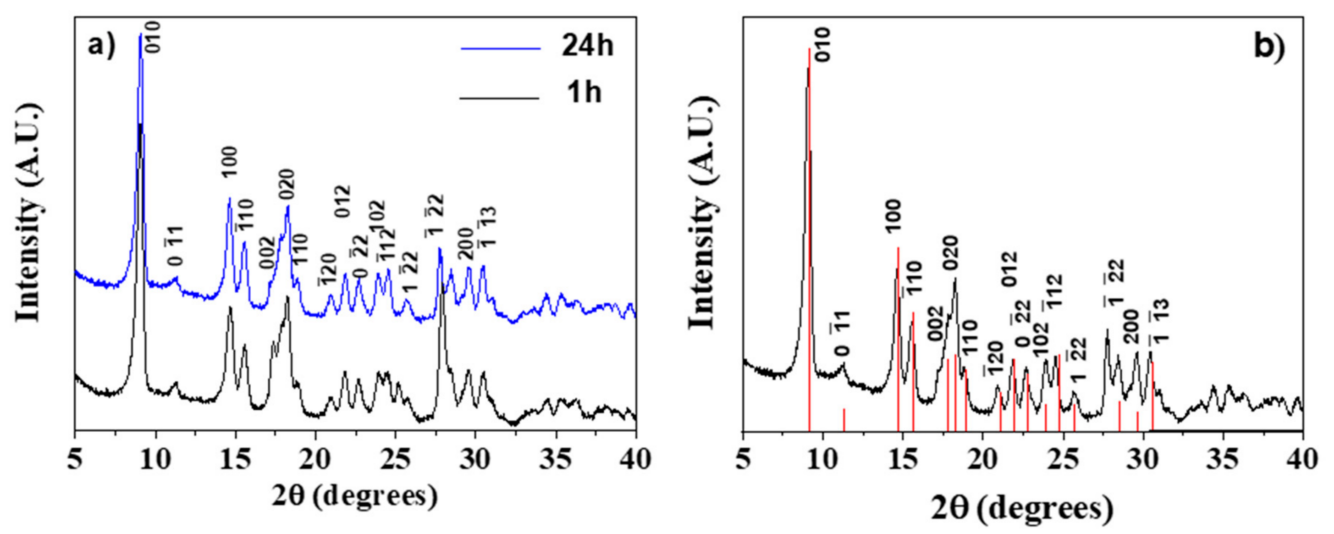

Figure 1. (a) Comparison of the X-ray powder patterns of the $\left[\mathrm{Gd}_{2}(\mathrm{BDC})_{3}\left(\mathrm{H}_{2} \mathrm{O}\right)_{4}\right]$ complex synthesized for 1 and $24 \mathrm{~h} ;(\mathbf{b}) \mathrm{X}$-ray powder pattern of the $\left[\mathrm{Gd}_{2}(\mathrm{BDC})_{3}\left(\mathrm{H}_{2} \mathrm{O}\right)_{4}\right]$ complex synthesized for $24 \mathrm{~h}$ assigned considering the powder pattern of the $\left[\mathrm{Tb}_{2}(\mathrm{BDC})_{3}\left(\mathrm{H}_{2} \mathrm{O}\right)_{4}\right]$ isomorph (red lines in the figure) derived from ref. [44] using the Mercury code [45].

In Figure $1 b$, the XRD pattern of the Gd-BDC sample, obtained from the $24 \mathrm{~h}$ synthesis, is reported and compared with the theoretical data of the $\left[\mathrm{Tb}_{2}(\mathrm{BDC})_{3}\left(\mathrm{H}_{2} \mathrm{O}\right)_{4}\right]$ isomorph [44]. It is important to highlight that the relative intensities of the studied sample are comparable to those of the powder pattern of the $\left[\mathrm{Tb}_{2}(\mathrm{BDC})_{3}\left(\mathrm{H}_{2} \mathrm{O}\right)_{4}\right]$ isomorph derived using the Mercury code [45]. Therefore, given the identical peak positions and intensities, the pattern has been attributed to the $\left[\mathrm{Gd}_{2}(\mathrm{BDC})_{3}\left(\mathrm{H}_{2} \mathrm{O}\right)_{4}\right]$ phase. $\mathrm{BDC}$ ligands are coordinated to $\mathrm{Gd}^{3+}$ ions and together with the water molecules complete the eight coordination, the most common for gadolinium monomeric complexes [46,47], giving rise to the 3D network.

A further validation of the $\left[\mathrm{Gd}_{2}(\mathrm{BDC})_{3}\left(\mathrm{H}_{2} \mathrm{O}\right)_{4}\right]$ structure has been obtained by the Fourier transform infrared spectroscopy (FT-IR). The spectra, recorded in the $4000-500 \mathrm{~cm}^{-1}$ range (Figure S1), provide evidence of the presence of $\mathrm{H}_{2} \mathrm{O}$ molecules in the coordination sphere of the metallic center as assessed by the presence of a broad band around $3450 \mathrm{~cm}^{-1}$. Other significant peaks are observed at 1540,1509, $1305 \mathrm{~cm}^{-1}$ and they are due to the stretching vibrations of the carboxylate $\mathrm{C}=\mathrm{O}$ group. Peaks in the fingerprint region $\left(1000-700 \mathrm{~cm}^{-1}\right)$ are due to the vibrational modes' characteristic of the benzene ring. Peaks at $2923 \mathrm{~cm}^{-1}$, at $1460 \mathrm{~cm}^{-1}$ and at $1377 \mathrm{~cm}^{-1}$ are due to the nujol used to prepare the mull. 
Finally, morphological characterization has been carried out through field emission scanning electron microscopy (FE-SEM) using a very low acceleration voltage of $3 \mathrm{kV}$ to avoid charging effects. FE-SEM images (Figure 2) show very homogeneous samples in terms of shape and dimensions.
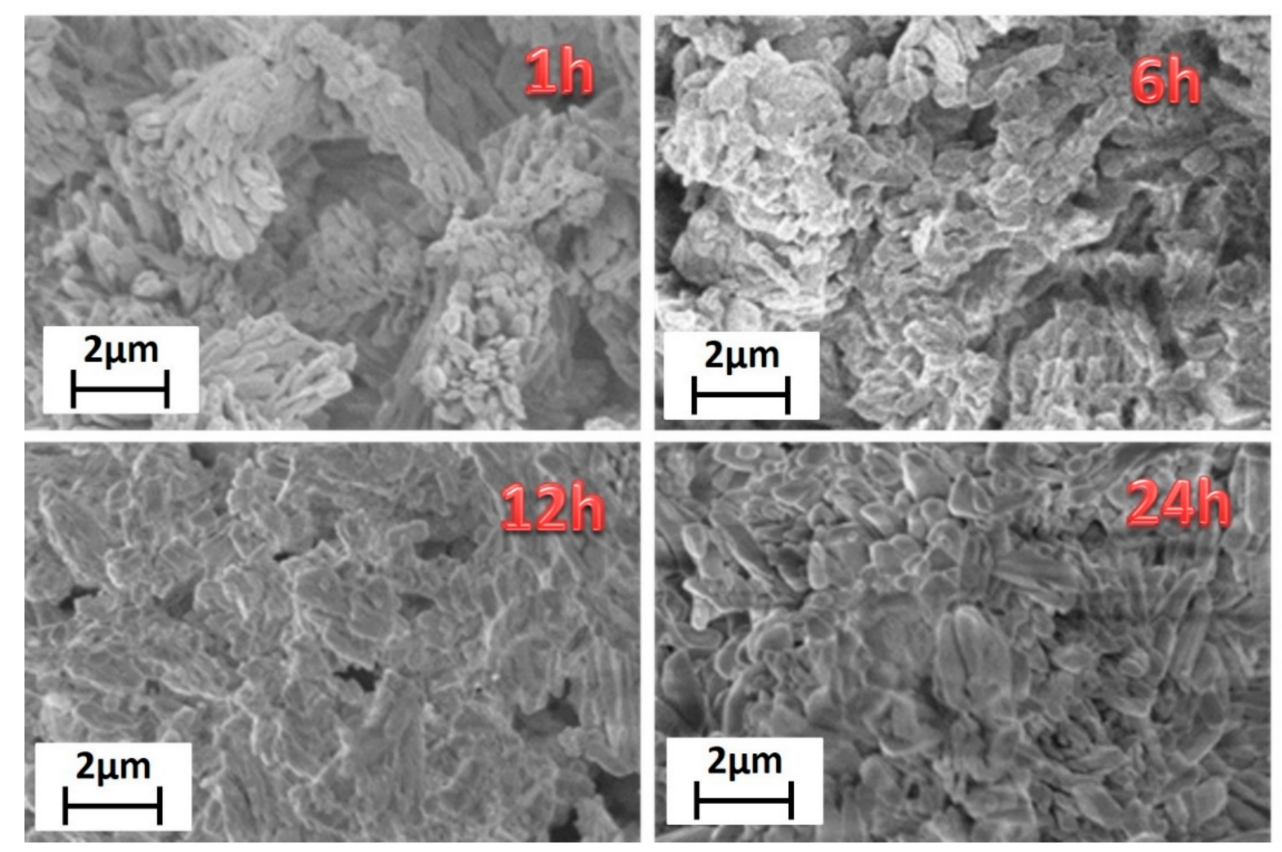

Figure 2. FE-SEM images of the $\left[\mathrm{Gd}_{2}(\mathrm{BDC})_{3}\left(\mathrm{H}_{2} \mathrm{O}\right)_{4}\right]$ synthesized for $1 \mathrm{~h}, 6 \mathrm{~h}, 12 \mathrm{~h}$ and $24 \mathrm{~h}$.

Lower reaction time, $1 \mathrm{~h}$, gives rise to bundles of nanorods of about $200-300 \mathrm{~nm}$ in diameter. Upon increasing the reaction time, the grain size increases, with dimensions of about $500-600 \mathrm{~nm}$ for the highest reaction time of $24 \mathrm{~h}$. This is due to the effect of temperature for a prolonged time that allows a sintering of the network structure yielding larger and more crystalline grains. The energy dispersive X-ray (EDX) analysis (Figure S2) confirms the formation of the Gd-MOF structure, the spectrum showing all the expected peaks: the $\mathrm{L}$ and $\mathrm{M}$ emission lines of $\mathrm{Gd}$ are observed in the $6-7.5 \mathrm{keV}$ range and at $1.2 \mathrm{keV}$, respectively; the $\mathrm{C} \mathrm{K} \alpha$ and $\mathrm{O} K \alpha$ peaks found at 0.28 and $0.52 \mathrm{keV}$, respectively; the $\mathrm{Au} \mathrm{M}$ peaks due to the sputtered layer around $2.1 \mathrm{keV}$.

\subsection{Structural, Morphological and Compositional Properties of $\left[G d_{2}(\mathrm{NDC})_{3}\left(\mathrm{H}_{2} \mathrm{O}\right)\right] \cdot 2\left(\mathrm{H}_{2} \mathrm{O}\right)$}

Analogously to the Gd-BDC samples, the Gd-NDC with the 2,6-naphthalendicarboxylic acid was synthesized using water as a solvent and changing the reaction time, from $1 \mathrm{~h}$ to $24 \mathrm{~h}$. In this case the reaction time has a slight effect on the crystallinity, as well. A comparison between the XRD patterns of Gd-NDC samples, obtained at 1 and $24 \mathrm{~h}$, is reported in Figure 3a. The structure has been assigned by comparing the XRD pattern to the powder patterns of the homologous Ln-NDC [48,49] derived using the Mercury code [45]. In Figure $3 b$, the pattern of the Gd-NDC MOF (blue line) is perfectly coincident with that of the $\left[\mathrm{Yb}_{2}(\mathrm{NDC})_{3}\left(\mathrm{H}_{2} \mathrm{O}\right)\right] \cdot 2\left(\mathrm{H}_{2} \mathrm{O}\right)$ (red line) [48]. Therefore, the structural arrangement of the NDC ligand and $\mathrm{H}_{2} \mathrm{O}$ molecules gives rise to the $\left[\mathrm{Gd}_{2}(\mathrm{NDC})_{3}\left(\mathrm{H}_{2} \mathrm{O}\right)\right] \cdot 2\left(\mathrm{H}_{2} \mathrm{O}\right)$ network with a coordination of 6 or 7 around Gd. 



Figure 3. (a) X-ray powder patterns of the Gd-NDC networks synthesized for 1 and 24 h; (b) assignment of the $\left[\mathrm{Gd}_{2}(\mathrm{NDC})_{3}\left(\mathrm{H}_{2} \mathrm{O}\right)\right] \cdot 2\left(\mathrm{H}_{2} \mathrm{O}\right)$ pattern (blue line) in comparison with the Mercury derived powder pattern of the homologous $\left[\mathrm{Yb}_{2}(\mathrm{NDC})_{3}\left(\mathrm{H}_{2} \mathrm{O}\right)\right] \cdot 2\left(\mathrm{H}_{2} \mathrm{O}\right)$ (red line, ref. [48]).

The coordination number of 6 or 7 is lower than the most commonly observed 8coordination for Gd monomeric complexes [46,47], but it is quite common for these systems where the presence of a ditopic linker gives rise to very complex networks.

A comment deserves the nature of water molecules found in the present Gd-NDC system, since there are both water molecules coordinated to the metal ions and free lattice water molecules.

This observation is further corroborated by the FT-IR spectra of the Gd-NDC, synthesized for 1, 6, 12, $24 \mathrm{~h}$ (Figure S3). These spectra provide evidence of the presence of two different kinds of very weak peaks in the range 3400 and $3700 \mathrm{~cm}^{-1}$ : a broad small peak at $3470 \mathrm{~cm}^{-1}$ and sharp small peaks at 3582 and $3635 \mathrm{~cm}^{-1}$. The different kind of peaks may be associated, respectively, with the coordinated water molecules and the free lattice $\mathrm{H}_{2} \mathrm{O}$ molecules linked to the cavity cage through H-bonds [50-52]. It is worth to note the difference between the IR spectra in this region for the Gd-NDC vs. the Gd-BDC systems (Figure 4), that further confirms the dissimilar water role in the two networks. In fact, the $\left[\mathrm{Gd}_{2}(\mathrm{BDC})_{3}\left(\mathrm{H}_{2} \mathrm{O}\right)_{4}\right]$ spectrum shows only one broad peak in the 3400-3700 $\mathrm{cm}^{-1}$ region confirming the $\mathrm{H}_{2} \mathrm{O}$ coordination proposed for the Gd-BDC network, while coordinated and free lattice $\mathrm{H}_{2} \mathrm{O}$ molecules give rise to the different peaks found for the $\left[\mathrm{Gd}_{2}(\mathrm{NDC})_{3}\left(\mathrm{H}_{2} \mathrm{O}\right)\right] \cdot 2\left(\mathrm{H}_{2} \mathrm{O}\right)$ system.

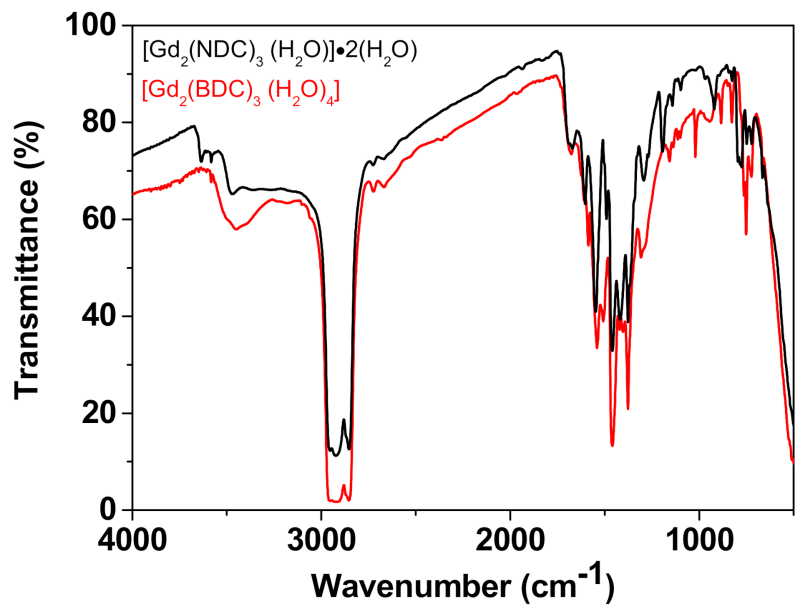

Figure 4. Comparison of the IR spectrum of the $\left[\mathrm{Gd}_{2}(\mathrm{NDC})_{3}\left(\mathrm{H}_{2} \mathrm{O}\right)\right] \cdot 2\left(\mathrm{H}_{2} \mathrm{O}\right)$ vs. the spectrum of the $\left[\mathrm{Gd}_{2}(\mathrm{BDC})_{3}\left(\mathrm{H}_{2} \mathrm{O}\right)_{4}\right]$.

Significant peaks are observed at 1603,1540,1416,1295, $1119 \mathrm{~cm}^{-1}$ and are due to vibrations of the functional groups of the carboxylate. Other peaks found in the fingerprint region (1000-700 $\mathrm{cm}^{-1}$ ) can be attributed to the vibrational modes' characteristic of the naphthalene ring. 
The FE-SEM images (Figure 5) show homogeneous and well-structured samples. The sample synthesized for $1 \mathrm{~h}$ has rod-like grains of about $200 \mathrm{~nm} \times 1000 \mathrm{~nm}$. The increasing of the reaction time affects not only the crystalline structure, but also the morphology that changes from rod-like to plate-like grains. For the longer reaction time of $24 \mathrm{~h}$ the grains are almost equidimensional and of the order of micrometers.

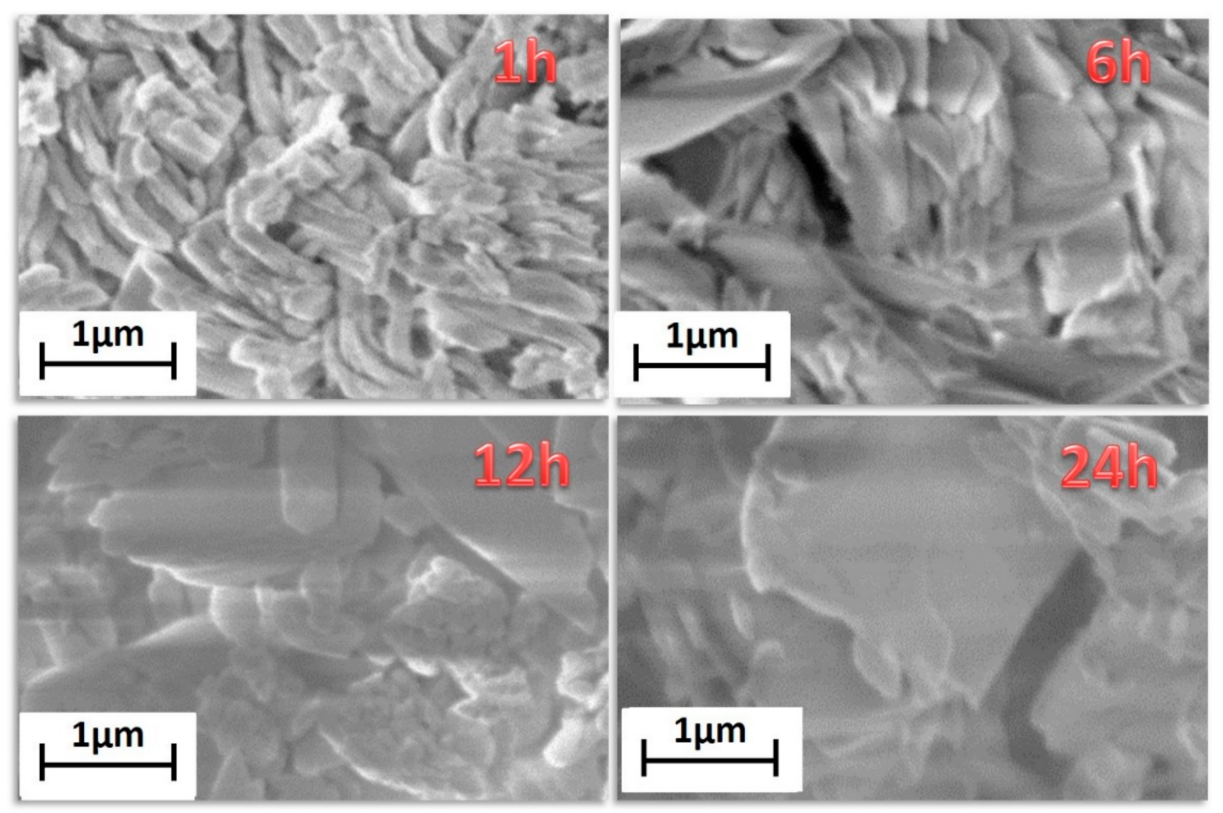

Figure 5. FE-SEM images of the $\left[\mathrm{Gd}_{2}(\mathrm{NDC})_{3}\left(\mathrm{H}_{2} \mathrm{O}\right)\right] \cdot 2\left(\mathrm{H}_{2} \mathrm{O}\right)$ synthesized for $1 \mathrm{~h}, 6 \mathrm{~h}, 12 \mathrm{~h}$ and $24 \mathrm{~h}$.

\subsection{Surface Area Measurements of Synthesized Gd-MOFs}

The Brunauer-Emmett-Teller (BET) method has been applied to characterize the networks in terms of surface area, in order to evaluate the textured properties of MOFs for applications as heterogeneous catalysts or sensing materials.

In order to correlate the processing variables to the structure/surface area of GdMOFs, the $\left[\mathrm{Gd}_{2}(\mathrm{BDC})_{3}\left(\mathrm{H}_{2} \mathrm{O}\right)_{4}\right]$ synthesized at $1 \mathrm{~h}$ and $24 \mathrm{~h}$ have been analyzed to compare products obtained for short and long reaction times. The FE-SEM images (Figure 2) show grain dimensions of about 200-300 nm for the sample synthesized in $1 \mathrm{~h}$, while for the $24 \mathrm{~h}$ treated sample the grains dimensions are in the range of 500-600 $\mathrm{nm}$. Therefore, it can be inferred that longer reaction times affect the grain dimensions, also determining a smaller surface area, which is $70 \pm 2 \mathrm{~m}^{2} / \mathrm{g}$ for the $24 \mathrm{~h}$ treated sample with respect to $83 \pm 2 \mathrm{~m}^{2} / \mathrm{g}$ for the $1 \mathrm{~h}$ treated one.

In the case of $\left[\mathrm{Gd}_{2}(\mathrm{NDC})_{3}\left(\mathrm{H}_{2} \mathrm{O}\right)\right] \cdot 2\left(\mathrm{H}_{2} \mathrm{O}\right)$, the obtained data indicate that for the synthesis carried out in $1 \mathrm{~h}$, the nanorod-like morphology (Figure 3 ) gives rise to a higher surface area of $75.2 \pm 0.2 \mathrm{~m}^{2} / \mathrm{g}$ with respect to the $24 \mathrm{~h}$ synthesis, which produces a platelike structures with larger dimensions and a consequent lower surface area $65 \pm 2 \mathrm{~m}^{2} / \mathrm{g}$.

In Table 1, surface areas and grain dimensions are compared, pointing to an effect of reaction time, which, in both cases, determine the formation of larger grains at $24 \mathrm{~h}$ and, consequently, smaller surface areas.

Table 1. Surface area and grain dimensions of the $1 \mathrm{~h}$ and $24 \mathrm{~h}$ Gd-MOF samples with BDC and NDC linkers.

\begin{tabular}{|c|c|c|c|c|}
\hline \multirow{3}{*}{$\begin{array}{c}\text { Sample } \\
\text { Reaction time } \\
\text { Surface area }\end{array}$} & \multicolumn{2}{|c|}{$\left[\mathrm{Gd}_{2}(\mathrm{BDC})_{3}\left(\mathrm{H}_{2} \mathrm{O}\right)_{4}\right]$} & \multicolumn{2}{|c|}{$\left[\mathrm{Gd}_{2}(\mathrm{NDC})_{3}\left(\mathrm{H}_{2} \mathrm{O}\right)\right] 2\left(\mathrm{H}_{2} \mathrm{O}\right)$} \\
\hline & $1 \mathrm{~h}$ & $24 \mathrm{~h}$ & $1 \mathrm{~h}$ & $24 \mathrm{~h}$ \\
\hline & $83 \pm 2 \mathrm{~m}^{2} / \mathrm{g}$ & $70 \pm 2 \mathrm{~m}^{2} / \mathrm{g}$ & $75.2 \pm 0.2 \mathrm{~m}^{2} / \mathrm{g}$ & $65 \pm 2 \mathrm{~m}^{2} / \mathrm{g}$ \\
\hline Grain dimensions & $200-300 \mathrm{~nm}$ & $500-600 \mathrm{~nm}$ & $300-350 \mathrm{~nm}$ & $900-1000 \mathrm{~nm}$ \\
\hline
\end{tabular}




\subsection{Sensing of Inorganic Ions}

As a proof of concept, the properties of the $\left[\mathrm{Gd}_{1.6} \mathrm{Eu}_{0.4}(\mathrm{BDC})_{3}\left(\mathrm{H}_{2} \mathrm{O}\right)_{4}\right]$ and the $\left[\mathrm{Gd}_{2}(\mathrm{BDC})_{3}\left(\mathrm{H}_{2} \mathrm{O}\right)_{4}\right]$ systems, as fluorescent probes, have been tested for the detection of the most common metals and toxic anions contaminants such as $\mathrm{Fe}^{3+}$ and $\mathrm{Cr}^{6+}$, respectively. The $1 \mathrm{~h}$ synthesis has been chosen for the Gd,Eu-BDC MOF, since the Gd-BDC synthesized for $1 \mathrm{~h}$ presents the higher surface area of $83 \pm 2 \mathrm{~m}^{2} / \mathrm{g}$ (see Table 1). Given the analogous ionic radii of $\mathrm{Eu}^{3+}$ and $\mathrm{Gd}^{3+}$, the Eu-doped $\mathrm{Gd}-\mathrm{BDC} \mathrm{MOF}$ is isostructural to the $\left[\mathrm{Gd}_{2}(\mathrm{BDC})_{3}\left(\mathrm{H}_{2} \mathrm{O}\right)_{4}\right]$, and thus it possesses a similar structure and characteristics.

A preliminary study of luminescence properties has been conducted through photoluminescence measurements in aqueous medium, using dispersions of the $\left[\mathrm{Gd}_{2}(\mathrm{BDC})_{3}\left(\mathrm{H}_{2} \mathrm{O}\right)_{4}\right]$, the $\left[\mathrm{Gd}_{2}(\mathrm{NDC})_{3}\left(\mathrm{H}_{2} \mathrm{O}\right)\right] \cdot\left(\mathrm{H}_{2} \mathrm{O}\right)_{2}$ and the $\left[\mathrm{Gd}_{1.6} \mathrm{Eu}_{0.4}(\mathrm{BDC})_{3}\left(\mathrm{H}_{2} \mathrm{O}\right)_{4}\right]$, respectively (see Figure $\mathrm{S} 4$ ). Both the BDC-based MOFs show fluorescence emission at $265 \mathrm{~nm}$ excitation, while the GdNDC MOF has been excited at $285 \mathrm{~nm}$. In particular, a broad emission occurs in the range of 400-450 nm for both the Gd-BDC and Gd,Eu-BDC systems and in the range of 350-400 nm for the Gd-NDC MOF, which may be attributed to a ligand-to-metal charge transfer [53]. The peak at $530 \mathrm{~nm}$ is a double-frequency scattering peak, whose wavelength is 2 times the excitation wavelength $(265 \mathrm{~nm})$. Moreover, the spectrum of the Gd,Eu-BDC MOF presents the characteristic emission of $\mathrm{Eu}^{3+}$ ion, with sharp and intense lines centered at 592 and $615 \mathrm{~nm}$, which can be ascribed to the ${ }^{5} \mathrm{D}_{0} \rightarrow{ }^{7} \mathrm{~F}_{1}$ and ${ }^{5} \mathrm{D}_{0} \rightarrow{ }^{7} \mathrm{~F}_{2}$ transitions, respectively. Furthermore, under UV irradiation a strong red emission can be easily observed also by the naked eye (see inset in Figure S4).

Firstly, the use of $\left[\mathrm{Gd}_{1.6} \mathrm{Eu}_{0.4}(\mathrm{BDC})_{3}\left(\mathrm{H}_{2} \mathrm{O}\right)_{4}\right] \mathrm{MOF}$ as sensing system has been tested for the detection of metal ions exploiting the excellent water stability and the high luminescent properties of the complex. Particularly, the as-prepared $\left[\mathrm{Gd}_{1.6} \mathrm{Eu}_{0.4}(\mathrm{BDC})_{3}\left(\mathrm{H}_{2} \mathrm{O}\right)_{4}\right]$ complex obtained at $1 \mathrm{~h}$ of synthesis has been dispersed into aqueous solution and different amounts of $\mathrm{Fe}^{3+} 1 \cdot \times 10^{-2} \mathrm{M}$ have been added to the suspension. Great care has been dedicated to have a homogeneous dispersion and to avoid any effect of sedimentation, thus the mixtures have been sonicated for $5 \mathrm{~min}$ after each addition to produce the metal ion-incorporated suspension for luminescent measurements. An incubation time of $5 \mathrm{~min}$ has been chosen to allow an optimal interaction between the MOF and the detected species. Particular attention has been devoted to the $\mathrm{pH}$ monitoring of the suspension during the sensing process to avoid instability of the detected species or the collapse of the MOF structure. This last phenomenon would be critical for the sensing process since the luminescence decrease would be related to the $\mathrm{pH}$ and not to the sensed species. The $\mathrm{pH}$ of the Eu-doped Gd-BDC system during the $\mathrm{Fe}^{3+}$ sensing detection varied from a 6.1 value at starting point ( $0 \mu \mathrm{L} \mathrm{Fe}^{3+}$ addition), to 4.2 at the end of the process (500 $\mu \mathrm{L} \mathrm{Fe}^{3+}$ addition). Conversely, the $\mathrm{pH}$ remains almost unchanged, from 6.1 to 5.7, for the sensing of the $\mathrm{Cr}_{2} \mathrm{O}_{7}{ }^{2-}$. The $\mathrm{pH}$ variation for the $\mathrm{Fe}^{3+}$ sensing is due to the hydrolysis of $\mathrm{Fe}^{3+}$. To confirm that the luminescence decrease is only dependent on the ion detection, luminescence spectra of the $\left[\mathrm{Gd}_{1.6} \mathrm{Eu}_{0.4}(\mathrm{BDC})_{3}\left(\mathrm{H}_{2} \mathrm{O}\right)_{4}\right]$ have been recorded in the $\mathrm{pH}$ range 3.5-6.0 (Figure 6). The intensity of the $\mathrm{Eu}^{3+}$ peak at $615 \mathrm{~nm}$ is almost independent on $\mathrm{pH}$ (inset Figure 6) in the investigated $\mathrm{pH}$ range, but at the lowest $\mathrm{pH}$ of 3.5 an increase of the band in the range $350-420 \mathrm{~nm}$ is likely due to the MOF structure collapse and formation of the free ligand [27]. The observed $\mathrm{pH}$ dependence is in accordance with literature data [26,29].

The result in Figure 7a reveals a strong quenching effect on the $\mathrm{Eu}^{3+}$ luminescent emission, already appreciable after the first addition of $20 \mu \mathrm{L}$ of $\mathrm{Fe}^{3+}$ contaminant. The intensity of both the ${ }^{5} \mathrm{D}_{0} \rightarrow{ }^{7} \mathrm{~F}_{1}$ and ${ }^{5} \mathrm{D}_{0} \rightarrow{ }^{7} \mathrm{~F}_{2}$ decreases significantly upon increasing the $\mathrm{Fe}^{3+}$ amounts. 


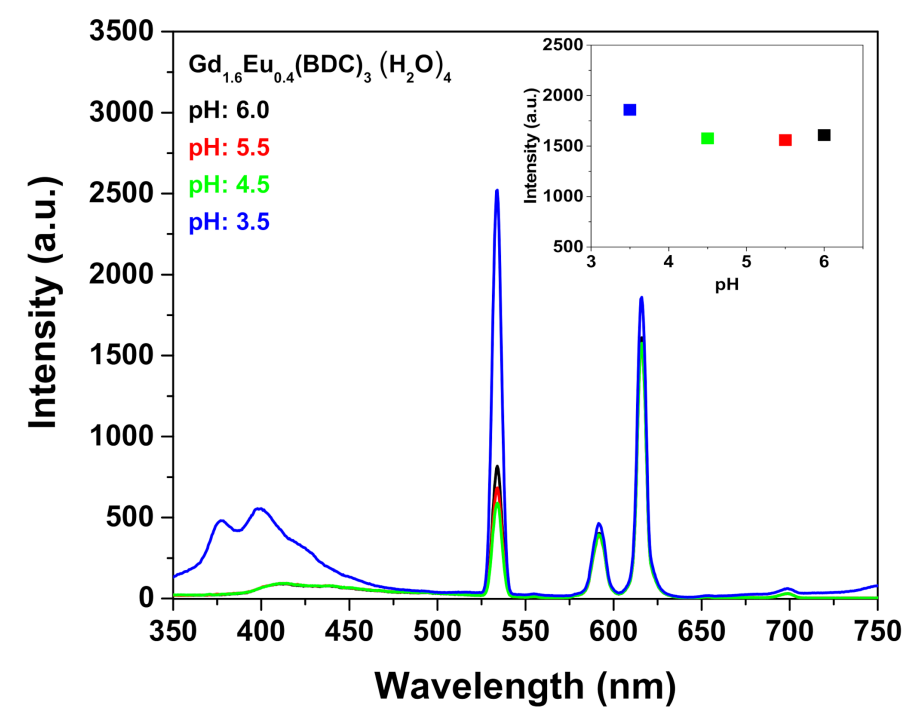

Figure 6. Emission spectra of the $\mathrm{Gd}_{1.6} \mathrm{Eu}_{0.4}(\mathrm{BDC})_{3}\left(\mathrm{H}_{2} \mathrm{O}\right)_{4}(2 \mathrm{mg})$ dispersed into aqueous solution at different $\mathrm{pH}$ under excitation at $265 \mathrm{~nm}$. The insert reports the intensity of the peak at $615 \mathrm{~nm}$ in the $\mathrm{pH}$ range 3.5-6.
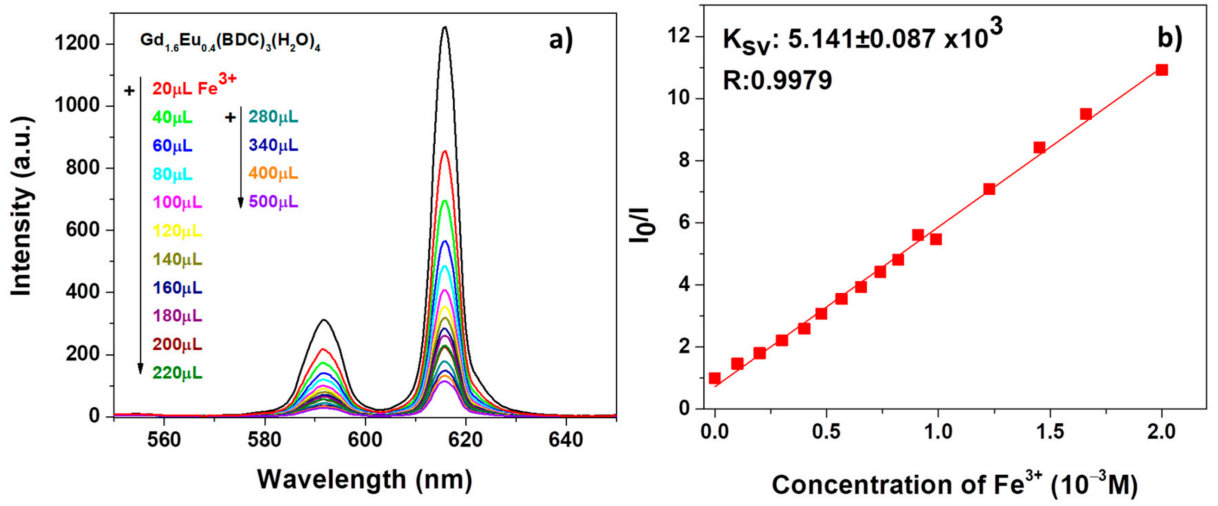

Figure 7. (a) Emission spectra and (b) Ksv curve $\mathrm{Gd}_{1.6} \mathrm{Eu}_{0.4}(\mathrm{BDC})_{3}\left(\mathrm{H}_{2} \mathrm{O}\right)_{4}(2 \mathrm{mg})$ dispersed into aqueous solution in the presence of various concentrations of $\mathrm{Fe}^{3+}$ under excitation at $265 \mathrm{~nm}$.

Similarly, promising sensing properties have been observed for the test on $\mathrm{Cr}_{2} \mathrm{O}_{7}{ }^{2-}$ solution as revealed in Figure 8a.
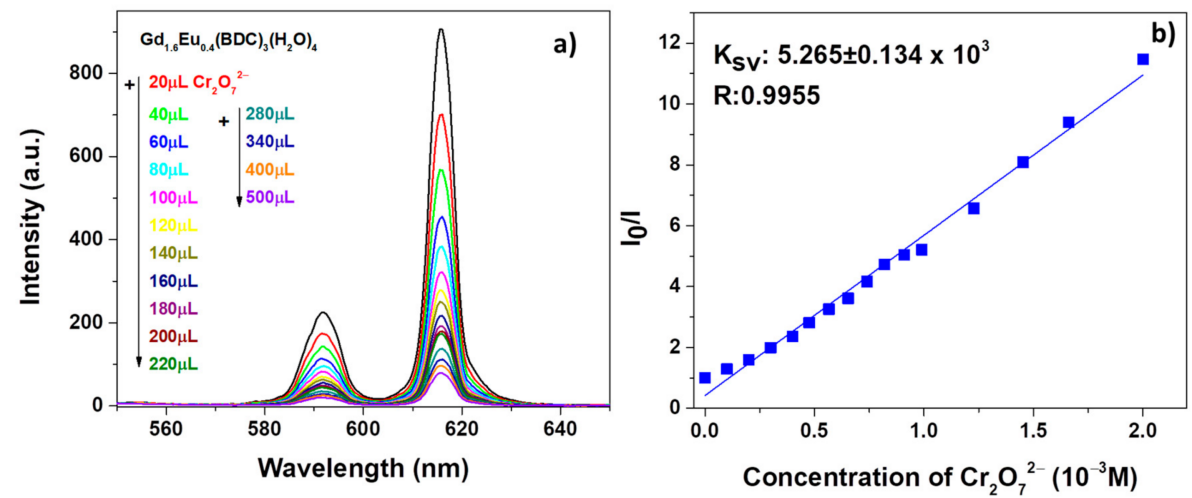

Figure 8. (a) Emission spectra and (b) Ksv curve $\mathrm{Gd}_{1.6} \mathrm{Eu}_{0.4}(\mathrm{BDC})_{3}\left(\mathrm{H}_{2} \mathrm{O}\right)_{4}(2 \mathrm{mg})$ dispersed into aqueous solution in the presence of various concentrations of $\mathrm{Cr}_{2} \mathrm{O}_{7}{ }^{2-}$ under excitation at $265 \mathrm{~nm}$. 
In order to have a quantitative estimation of the phenomena, the quenching effect has been rationalized by the Stern-Volmer equation [54] (see Figures $7 \mathrm{~b}$ and $8 b$ ):

$$
\mathrm{I}_{0} / \mathrm{I}=1+\mathrm{K}_{\mathrm{sv}}[\mathrm{M}]
$$

in which $\mathrm{I}_{0}$ and $\mathrm{I}$ are the intensity values of the most intense peaks $(615 \mathrm{~nm})$ of the $\mathrm{Gd}_{1.6} \mathrm{Eu}_{0.4}(\mathrm{BDC})_{3}\left(\mathrm{H}_{2} \mathrm{O}\right)_{4}$ spectrum in the absence and presence of analytes, $\mathrm{Ksv}$ is the quenching constant and [M] is the analyte absolute concentration [55]. For both systems, in Figures $7 b$ and $8 b$, the linear coefficients $R$, very close to 1 , point to linear correlations and so a good fit of the Stern-Volmer equation model. In addition, the quenching effect on the luminescence of $\mathrm{Gd}_{1.6} \mathrm{Eu}_{0.4}(\mathrm{BDC})_{3}\left(\mathrm{H}_{2} \mathrm{O}\right)_{4}$ has been quantitatively estimated through the Ksv values, which have been calculated as $5.141 \times 10^{3}$ and $5.265 \times 10^{3} \mathrm{for} \mathrm{Fe}^{3+}$ and $\mathrm{Cr}_{2} \mathrm{O}_{7}{ }^{2-}$, respectively. The derived values of Ksv point to a strong quenching effect on the $\mathrm{Eu}^{3+}$ luminescence and thus a high sensitivity of the Eu-doped Gd-BDC MOF to ions detection. The presently found values are in accordance with literature data [56-58], and this represents a promising result considering that, in the present case, only an Eu-doped sample is used and thus the test would be a cost-effective sensing process, with respect to pure Eu-MOF structures.

Finally, to better understand the sensing phenomena, an accurate check of both framework structure and composition has been performed through XRD and EDX analysis on the $\mathrm{Gd}_{1.6} \mathrm{Eu}_{0.4}(\mathrm{BDC})_{3}\left(\mathrm{H}_{2} \mathrm{O}\right)_{4}$ system before and after the $\mathrm{Fe}^{3+}$ sensing test. Three main causes may be responsible for the alteration of the MOF luminescence: (a) damage of the crystal structure; (b) cation exchange between the MOF ion and the sensed cations; and (c) physisorption interactions between the sensed species and the framework. The XRD pattern of Gd,Eu-BDC MOF after the detection of $\mathrm{Fe}^{3+}$ is identical to the untreated one (see Figure S5), thus proving that the structure is maintained. In addition, the EDX analysis supports this observation, since it does not reveal the presence of any $\mathrm{Fe}^{3+}$ contaminant within the detectability limit of the technique (Figure S6). These findings confirm that the framework structure remains unchanged after the test proving that the MOF framework is stable in the aqueous solution of $\mathrm{Fe}^{3+}$ ions and the fluorescence quenching phenomena is not due to the collapse of the crystal framework structures. The most likely prominent mechanism is the physisorption of $\mathrm{Fe}^{3+}$, which quenches the Eu luminescence [56]. Nevertheless, a comprehensive study on the nature of interaction would require much more time and investigation. Finally, MOFs' size, after their applications in the ion sensing test, has been determined through FE-SEM images. Unfortunately, it is not possible to see disperse particles, but aggregates are visible (Figure S7). This could not be avoided since the samples have to be prepared by dropping the dispersion on an SEM Al stub and during water evaporation aggregation occurs.

These data point on one hand to assume that just a physisorption process occurs during the sensing test and, on the other hand, they confirm the high stability of the $\mathrm{Gd}_{1.6} \mathrm{Eu}_{0.4}(\mathrm{BDC})_{3}\left(\mathrm{H}_{2} \mathrm{O}\right)_{4}$ system in water solution and after sensing applications.

In order to assess the reusable performance of the Gd,Eu-BDC MOF, sequential $\mathrm{Fe}^{3+}$ detection tests, using the same powder have been carried out repeatedly for three times (Figures S8 and S9). After each test the powder has been carefully washed, centrifuged and reused. The $\mathrm{pH}$ was monitored during the tests as well.

The pure Gd-BDC MOF has been also applied for the detection of the same ions, i.e., $\mathrm{Fe}^{3+}$ and $\mathrm{Cr}_{2} \mathrm{O}_{7}{ }^{2-}$, using identical procedures to those used for the tests with the $\mathrm{Gd}$, $\mathrm{Eu}$ BDC MOF. Results of the test done with $\mathrm{Fe}^{3+}$ ions (Figure S10a) indicate that the Gd-BDC MOF system does not respond to the $\mathrm{Fe}^{3+}$ detection, since a constant intensity of the broad emission between 400 and $550 \mathrm{~nm}$ is observed, as confirmed by the $\mathrm{K}_{\mathrm{SV}}$ value (Figure S10b), whose error is higher than the value itself. This means that neither the band due to the ligand-to-metal charge transfer nor the specific band emission of $\mathrm{Gd}$ are sensitive to the $\mathrm{Fe}^{3+}$ detection. At difference, the Gd-BDC MOF is functional for the $\mathrm{Cr}_{2} \mathrm{O}_{7}{ }^{2-}$ sensing, since the emission of both bands decreases upon $\mathrm{Cr}_{2} \mathrm{O}_{7}{ }^{2-}$ addition (Figure S11a) and a $\mathrm{K}_{\mathrm{SV}}$ value of $2.913 \times 10^{3}$ is found (Figure S11b). Nevertheless, considering the low intensity of the 
Gd emission spectra with respect to the Gd,Eu-BDC MOF, the Eu doped system is overall more suited for ion detection.

\section{Conclusions}

The focus of this work is the development of a green, one-pot synthetic procedure for the preparation of Gd-MOFs and Gd,Eu-MOFs using the 1,4-benzenedicarboxylic acid or 2,6-naphthalenedicarboxylic acid as ditopic ligands. The syntheses were carried out from commercially available reagents, such as the $\mathrm{Gd}$ or Eu acetate salt, in $\mathrm{H}_{2} \mathrm{O}$ solvent and under mild operating conditions, ambient pressure and relatively short times from $1 \mathrm{~h}$ to $24 \mathrm{~h}$. A systematic study has allowed to correlate the Gd-MOF textural properties to the synthetic processing conditions. The Gd-BDC and the Gd,Eu-BDC MOFs, synthesized in $1 \mathrm{~h}$, have been applied to sensing inorganic ions, such as the $\mathrm{Fe}^{3+}$ and $\mathrm{Cr}_{2} \mathrm{O}_{7}{ }^{2-}$, in water solution yielding results comparable to materials obtained through the solvothermal process. Validation of applicability of the present system has been assessed through sequential ion detection tests, using the same powder for three times. These findings represent a great advantage if compared with data reported in the literature where the solvothermal synthesized MOFs, requiring days of reaction time and organic solvent such as dimethylformamide, are applied. In addition, the high stability in water of presently synthesized Ln-BDC MOFs accomplishes the mandatory requirement that they need to be stable in aqueous solution for real applications. These results indicate that the presently reported Eu-doped Gd MOF systems are suitable for inorganic ion detection and may be applied in various different sensing tests.

Supplementary Materials: The following are available online at https:/ /www.mdpi.com/1424-8 220/21/5/1679/s1, Figure S1: IR spectra of the Gd-BDC; Figure S2: EDX spectrum of the Gd-BDC; Figure S3: IR spectra of the Gd-NDC; Figure S4: Photoluminescence spectra of the Gd-BDC and Gd-NDC; Figure S5: XRD patterns of the Gd,Eu-BDC before and after $\mathrm{Fe}^{3+}$ sensing test; Figure S6: EDX spectra of the $\mathrm{Gd}, \mathrm{Eu}-\mathrm{BDC}$ before and after $\mathrm{Fe}^{3+}$ sensing test; Figures $\mathrm{S} 7$ and S8: Second and third run of $\mathrm{Fe}^{3+}$ detection using Gd,Eu-BDC; Figure S9: $\mathrm{Fe}^{3+}$ sensing test using the Gd-BDC; Figure S10: $\mathrm{Cr}_{2} \mathrm{O}_{7}{ }^{2-}$ sensing test using the Gd-BDC.

Author Contributions: Conceptualization, A.L.P.; validation, S.S. and G.M.; investigation, R.P. and R.F.; writing—original draft preparation, A.L.P.; writing—review and editing, G.M.; funding acquisition, G.M. All authors have read and agreed to the published version of the manuscript.

Funding: This research was funded by University of Catania within the PIACERI research program UNICT 2020-22 Linea 2.

Data Availability Statement: The data presented in this study are available in the article and supplementary material.

Acknowledgments: The authors thank the Bio-nanotech Research and Innovation Tower (BRIT) laboratory of the University of Catania (Grant no. PONa3_00136 financed by the MIUR) for the Smartlab diffractometer facility.

Conflicts of Interest: The authors declare no conflict of interest.

\section{References}

1. Dhakshinamoorthy, A.; Asiri, A.M.; Garcia, H. Metal-Organic Framework (MOF) Compounds: Photocatalysts for Redox Reactions and Solar Fuel Production. Angew. Chem. Int. Ed. 2016, 55, 5414-5445. [CrossRef]

2. So, M.C.; Wiederrecht, G.P.; Mondloch, J.E.; Hupp, J.T.; Farha, O.K. Metal-organic framework materials for light-harvesting and energy transfer. Chem. Commun. 2015, 51, 3501-3510. [CrossRef] [PubMed]

3. Li, J.; Bhatt, P.M.; Li, J.; Eddaoudi, M.; Liu, Y. Recent Progress on Microfine Design of Metal-Organic Frameworks: Structure Regulation and Gas Sorption and Separation. Adv. Mater. 2020, 32, 2002563. [CrossRef] [PubMed]

4. Connolly, B.M.; Madden, D.G.; Wheatley, A.E.H.; Fairen-Jimenez, D. Shaping the Future of Fuel: Monolithic Metal-Organic Frameworks for High-Density Gas Storage. J. Am. Chem. Soc. 2020, 142, 8541-8549. [CrossRef]

5. Li, B.; Wen, H.-M.; Zhou, W.; Chen, B. Porous Metal-Organic Frameworks for Gas Storage and Separation: What, How, and Why? J. Phys. Chem. Lett. 2014, 5, 3468-3479. [CrossRef] [PubMed] 
6. Wu, H.; Gong, Q.; Olson, D.H.; Li, J. Commensurate Adsorption of Hydrocarbons and Alcohols in Microporous Metal Organic Frameworks. Chem. Rev. 2012, 112, 836-868. [CrossRef]

7. Yang, L.; Qian, S.; Wang, X.; Cui, X.; Chen, B.; Xing, H. Energy-efficient separation alternatives: Metal-organic frameworks and membranes for hydrocarbon separation. Chem. Soc. Rev. 2020, 49, 5359-5406. [CrossRef]

8. Cui, Y.; Chen, B.; Qian, G. Lanthanide metal-organic frameworks for luminescent sensing and light-emitting applications. Coord. Chem. Rev. 2014, 273, 76-86. [CrossRef]

9. Lee, J.-H.; Nguyen, T.-B.; Nguyen, D.-K.; Kim, J.-H.; Kim, J.Y.; Phan, B.T.; Kim, S.S. Gas Sensing Properties of Mg-Incorporated Metal-Organic Frameworks. Sensors 2019, 19, 3323. [CrossRef]

10. Corma, A.; Garcia, H.; Llabres i Xamena, F.X. Engineering Metal Organic Frameworks for Heterogeneous Catalysis. Chem. Rev. 2010, 110, 4606-4655. [CrossRef] [PubMed]

11. Konnerth, H.; Matsagar, B.M.; Chen, S.S.; Prechtl, M.H.G.; Shieh, F.K.; Wu, K.C.-W. Metal-organic framework (MOF)-derived catalysts for fine chemical production. Coord. Chem. Rev. 2020, 416, 213319. [CrossRef]

12. Gascon, J.; Corma, A.; Kapteijn, F.; Llabres i Xamena, F.X. Metal Organic Framework Catalysis: Quo vadis? ACS Catal. 2014, 4, 361-378. [CrossRef]

13. Zhang, W.; Xiong, R.-G. Ferroelectric Metal-Organic Frameworks. Chem. Rev. 2012, 112, 1163-1195. [CrossRef]

14. Cui, Y.; Li, B.; He, H.; Zhou, W.; Chen, B.; Qian, G. Metal-Organic Frameworks as Platforms for Functional Materials. Acc. Chem. Res. 2016, 49, 483-493. [CrossRef]

15. Chueh, C.-C.; Chen, C.-I.; Su, Y.-A.; Konnerth, H.; Gu, Y.J.; Kung, C.-W.; Wu, K.C.-W. Harnessing MOF materials in photovoltaic devices: Recent advances, challenges, and perspectives. J. Mater. Chem. A 2019, 7, 17079-17095. [CrossRef]

16. Li, M.; Li, D.; O’Keeffe, M.; Yaghi, O.M. Topological Analysis of Metal-Organic Frameworks with Polytopic Linkers and/or Multiple Building Units and the Minimal Transitivity Principle. Chem. Rev. 2014, 114, 1343-1370. [CrossRef] [PubMed]

17. Guo, H.; Wang, M.; Liu, J.; Zhu, S.; Liu, C. Facile synthesis of nanoscale high porosity IR-MOFs for low-k dielectrics thin films. Microporous Mesoporous Mater. 2016, 221, 40-47. [CrossRef]

18. Hausdorf, S.; Baitalow, F.; Böhle, T.; Rafaja, D.; Mertens, F.O.R.L. Main-Group and Transition-Element IRMOF Homologues. J. Am. Chem. Soc. 2010, 132, 10978-10981. [CrossRef] [PubMed]

19. Tsai, M.J.; Li, C.Y.; Wu, J.Y. Luminescent $\mathrm{Zn}(\mathrm{II})$ coordination polymers as efficient fluorescent sensors for highly sensitive detection of explosive nitroaromatics. Cryst. Eng. Comm. 2018, 20, 6762-6774. [CrossRef]

20. Mueller, U.; Schubert, M.; Teich, F.; Puetter, H.; Schierle-Arndt, K.; Pastre, J. Metal-organic frameworks-prospective industrial applications. J. Mater. Chem. 2006, 16, 626-636. [CrossRef]

21. Monforte, F.; Falsaperna, M.; Pellegrino, A.L.; Bongiorno, C.; Motta, A.; Mannino, G.; Condorelli, G.G. Direct Growth on Si(100) of Isolated Octahedral Mil-101(Fe) Crystals for the Separation of Aromatic Vapors. J. Phys. Chem. C 2019, 123, 28836-28845. [CrossRef]

22. Abrori, S.A.; Septiani, N.L.W.; Nugraha, A.I.; Suyatman, S.V.; Yuliarto, B. Metal-Organic-Framework FeBDC-Derived Fe $\mathrm{O}_{4}$ for Non-Enzymatic Electrochemical Detection of Glucose. Sensors 2020, 20, 4891. [CrossRef]

23. Guillou, O.; Daiguebonne, C.; Calvez, G.; Bernot, K. A Long Journey in Lanthanide Chemistry: From Fundamental Crystallogenesis Studies to Commercial Anticounterfeiting Taggants. Acc. Chem. Res. 2016, 49, 844-856. [CrossRef]

24. Younis, S.A.; Bhardwaj, N.; Bhardwaj, S.K.; Kim, K.-H.; Deep, A. Rare earth metal-organic frameworks (RE-MOFs): Synthesis, properties, and biomedical applications. Coord. Chem. Rev. 2020. Ahead of print. [CrossRef]

25. Fordham, S.; Wang, X.; Bosch, M.; Zhou, H.-C. Lanthanide Metal-Organic Frameworks in Structure and Bonding; Springer: Berlin/Heidelberg, Germany, 2015; Volume 163, pp. 1-27.

26. Tao, Y.; Zhang, P.; Liu, J.; Chen, X.; Guo, X.; Jin, H.; Chai, J.; Wang, L.; Fan, Y. Multi-responsive luminescent sensor based on three dimensional lanthanide metal-organic framework. New J. Chem. 2018, 42, 19485-19493. [CrossRef]

27. Hao, J.N.; Yan, B. Amino-decorated lanthanide(III) organic extended frameworks for multi-color luminescence and fluorescence sensing. J. Mater. Chem. C 2014, 2, 6758-6764. [CrossRef]

28. Li, J.M.; Liab, R.; Li, X. Construction of metal-organic frameworks (MOFs) and highly luminescent Eu(III)-MOF for the detection of inorganic ions and antibiotics in aqueous medium. CrystEngComm 2018, 20, 4962-4972. [CrossRef]

29. Du, Y.; Yang, H.; Liu, R.; Shao, C.; Yang, L. A multi-responsive chemosensor for highly sensitive and selective detection of $\mathrm{Fe}^{3+}, \mathrm{Cu}^{2+}, \mathrm{Cr}_{2} \mathrm{O}_{7}{ }^{2-}$ and nitrobenzene based on a luminescent lanthanide metal-organic framework. Dalton Trans. 2020, 49, 13003-13016. [CrossRef]

30. Gai, Y.-L.; Guo, Q.; Zhao, X.-Y.; Chen, Y.; Liu, S.; Zhang, Y.; Zhuo, C.-X.; Yao, C.; Xiong, K.-C. Extremely stable europium-organic framework for luminescent sensing of $\mathrm{Cr}_{2} \mathrm{O}_{7}{ }^{2-}$ and $\mathrm{Fe}^{3+}$ in aqueous systems. Dalton Trans. 2018, 47, 12051-12055. [CrossRef] [PubMed]

31. Duan, L.; Zhang, C.; Cen, P.; Jin, X.; Liang, C.; Yang, J.; Liu, X. Stable Ln-MOFs as multi-responsive photoluminescence sensors for the sensitive sensing of $\mathrm{Fe}^{3+}, \mathrm{Cr}_{2} \mathrm{O}_{7}{ }^{2-}$, and nitrofuran. CrystEngComm 2020, 22, 1695-1704. [CrossRef]

32. Ren, K.; Wu, S.H.; Guo, X.F.; Wang, H. Lanthanide Organic Framework as a Reversible Luminescent Sensor for Sulfamethazine Antibiotics. Inorg. Chem. 2019, 58, 4223-4229. [CrossRef]

33. He, N.; Gao, M.; Shen, D.; Li, H.; Han, Z.; Zhao, P. Rapid visual detection of nitroaromatic explosives using a luminescent europium-organic framework material. Forensic Sci. Int. 2019, 297, 1-7. [CrossRef] [PubMed] 
34. Zhao, Y.; Wan, M.-Y.; Bai, J.-P.; Zeng, H.; Lu, W.; Li, D. pH-Modulated luminescence switching in a Eu-MOF: Rapid detection of acidic amino acids. J. Mater. Chem. C 2019, 7, 11127-11133. [CrossRef]

35. Cui, Z.; Zhang, X.; Liu, S.; Zhou, L.; Li, W.; Zhang, J. Anionic Lanthanide Metal-Organic Frameworks: Selective Separation of Cationic Dyes, Solvatochromic Behavior, and Luminescent Sensing of Co(II) Ion. Inorg. Chem. 2018, 57, 11463-11473. [CrossRef] [PubMed]

36. Zhu, Y.; Wang, L.; Chen, X.; Wang, P.; Fan, Y.; Zhang, P. 3D lanthanide metal-organic frameworks constructed from 2,6naphthalenedicarboxylate ligand: Synthesis, structure, luminescence and dye adsorption. J. Solid State Chem. 2017, 251, 248-254. [CrossRef]

37. Xu, Q.W.; Dong, G.; Cui, R.; Li, X. 3D lanthanide-coordination frameworks constructed by a ternary mixed-ligand: Crystal structure, luminescence and luminescence sensing. CrystEngComm 2020, 22, 740-750. [CrossRef]

38. Silva do Nascimento, J.F.; Barros, B.S.; Kulesza, J.; Lucena de Oliveira, J.B.; Pereira Leite, A.K.; Silva de Oliveira, R. Influence of synthesis time on the microstructure and photophysical properties of Gd-MOFs doped with Eu ${ }^{3+}$. Mater. Chem. Phys. 2017, 190, 166-174. [CrossRef]

39. Alammar, T.; Hlova, I.Z.; Gupta, S.; Biswas, A.; Ma, T.; Zhou, L.; Balema, V.; Pecharsky, V.K.; Mudring, A.-V. Mechanochemical synthesis, luminescent and magnetic properties of lanthanide benzene-1,4-dicarboxylate coordination polymers $\left(\operatorname{Ln}_{0.5} \mathrm{Gd}_{0.5}\right)_{2}(1,4-$ $\mathrm{BDC})_{3}\left(\mathrm{H}_{2} \mathrm{O}\right)_{4} ; \mathrm{Ln}=\mathrm{Sm}, \mathrm{Eu}, \mathrm{Tb}$. New J. Chem. 2020, 44, 1054-1062. [CrossRef]

40. Reinsch, H. “Green” Synthesis of Metal-Organic Frameworks. Eur. J. Inorg. Chem. 2016, 27, 4290-4299. [CrossRef]

41. Sing, K.S.W.; Everett, D.H.; Haul, R.A.W.; Moscou, P.R.A.; Rouquerol, J.; Siemieniewska, T. Reporting physisorption data for gas/solid systems with special reference to the determination of surface area and porosity. Pure Appl. Chem. 1985, 57, 603-619. [CrossRef]

42. Daiguebonne, C.; Kerbellec, N.; Guillou, O.; Bunzli, J.-C.; Gumy, F.; Catala, L.; Mallah, T.; Audebrand, N.; Gerault, Y.; Bernot, K.; et al. Structural and luminescent properties of micro- and nanosized particles of lanthanide terephthalate coordination polymers. Inorg. Chem. 2008, 47, 3700-3708. [CrossRef]

43. Kerbellec, N.; Kustaryono, D.; Haquin, V.; Etienne, M.; Daiguebonne, C.; Guillou, O. An Unprecedented Family of LanthanideContaining Coordination Polymers with Highly Tunable Emission Properties. Inorg. Chem. 2009, 48, 2837-2843. [CrossRef] [PubMed]

44. Reineke, T.M.; Eddaoudi, M.; Fehr, M.; Kelley, D.; Yaghi, O.M. From Condensed Lanthanide Coordination Solids to Microporous Frameworks Having Accessible Metal Sites. J. Am. Chem. Soc. 1999, 121, 1651-1657. [CrossRef]

45. Mercury 3.7, Free Program of the Cambridge Crystallographic Database, New Features for the Visualization and Investigation of Crystal Structures

46. Malandrino, G.; Fragalà, I.L. Lanthanide "second-generation" precursors for MOCVD applications: Effects of the metal ionic radius and polyether length on coordination spheres and mass-transport properties. Coord. Chem. Rev. 2006, 250, 1605-1620. [CrossRef]

47. Malandrino, G.; Incontro, O.; Castelli, F.; Fragala, I.L.; Benelli, C. Synthesis, Characterization, and Mass-Transport Properties of Two Novel Gadolinium(III) Hexafluoroacetylacetonate Polyether Adducts: Promising Precursors for MOCVD of GdF 3 Films. Chem. Mater. 1996, 8, 1292-1297. [CrossRef]

48. Almeida Paz, F.A.; Klinowski, J. Hydrothermal synthesis of a novel thermally stable three-dimensional ytterbium-organic framework. Chem. Commun. 2003, 1484-1485. [CrossRef]

49. Zheng, X.; Sun, C.; Lu, S.; Liao, F.; Gao, S.; Jin, L. New porous lanthanide-organic frameworks: Synthesis, characterization, and properties of lanthanide 2,6-naphthalenedicarboxylates. Eur. J. Inorg. Chem. 2004, 3262-3268. [CrossRef]

50. Jiang, J.; Yaghi, O.M. Bronsted Acidity in Metal-Organic Frameworks. Chem. Rev. 2015, 115, 6966-6997. [CrossRef] [PubMed]

51. Volkringer, C.; Leclerc, H.; Lavalley, J.-C.; Loiseau, T.; Ferey, G.; Daturi, M.; Vimont, A. Infrared Spectroscopy Investigation of the Acid Sites in the Metal-Organic Framework Aluminum Trimesate MIL-100(Al). J. Phys. Chem. C 2012, 116, 5710-5719. [CrossRef]

52. Vimont, A.; Leclerc, H.; Mauge, F.; Daturi, M.; Lavalley, J.-C.; Surble, S.; Serre, C.; Férey, G. Creation of Controlled Bronsted Acidity on a Zeotypic Mesoporous Chromium(III) Carboxylate by Grafting Water and Alcohol Molecules. J. Phys. Chem. C 2007, 111, 383-388. [CrossRef]

53. Cui, Y.J.; Yue, Y.F.; Qian, G.D.; Chen, B.L. Luminescent Functional Metal-Organic Frameworks. Chem. Rev. 2012, 112, 1126-1162. [CrossRef] [PubMed]

54. Turro, N.J. Modern Molecular Photochemistry; University Science Books: Sausalito, CA, USA, 1991.

55. Xu, X.-Y.; Yan, B. Eu(III)-Functionalized MIL-124 as Fluorescent Probe for Highly Selectively Sensing Ions and Organic Small Molecules Especially for Fe(III) and Fe(II). ACS Appl. Mater. Interfaces 2015, 7, 721-729. [CrossRef] [PubMed]

56. Zhan, Z.; Liang, X.; Zhang, X.; Jia, Y.; Hu, M. A water-stable europium-MOF as a multifunctional luminescent sensor for some trivalent metal ions $\left(\mathrm{Fe}^{3+}, \mathrm{Cr}^{3+}, \mathrm{Al}^{3+}\right), \mathrm{PO}_{4}{ }^{3-}$ ions, and nitroaromatic explosives. Dalton Trans. 2019, 48, 1786-1794. [CrossRef]

57. Li, H.; Han, Y.; Shao, Z.; Li, N.; Huang, C.; Hou, H. Water-stable Eu-MOF fluorescent sensors for trivalent metal ions and nitrobenzene. Dalton Trans. 2017, 46, 12201-12208. [CrossRef] [PubMed]

58. Zhao, J.-J.; Liu, P.-Y.; Dong, Z.-P.; Liu, Z.-L.; Wang, Y.-Q. Eu(III)-organic framework as a multi-responsive photoluminescence sensor for efficient detection of 1-naphthol, $\mathrm{Fe}^{3+}$ and $\mathrm{MnO}^{4-}$ in water. Inorg. Chim. Acta 2020, 511, 119843. [CrossRef] 